\title{
Small-scale spatial structure and long-term variability of near- bottom layers in the HEBBLE area
}

\author{
Tal Ezer ${ }^{1}$ and Georges L. Weatherly \\ Department of Oceanography, Florida State University, Tallahassee, FL 32306, USA
}

(Received April 1988; revision accepted September 1989)

\begin{abstract}
Ezer, T. and Weatherly, G.L., 1991. Small-scale spatial structure and long-term variability of near-bottom layers in the HEBBLE area. In: A.R.M. Nowell (Editor), Deep Ocean Sediment Transport. Mar. Geol., 99: 319-328.

Analysis of $\sim 4$ years of deep-ocean measurements in the HEBBLE area indicate significant mean spatial differences in bottom layer velocities as well as temperatures associated with the Cold Filament. The data indicate that the Cold Filament core (potential temperature less than $1.80^{\circ} \mathrm{C}$ ) is order $7 \mathrm{~km}$ wide, comparable to the Rossby radius of deformation, and its location can fluctuate across slope in a range about four times larger than its instantaneous width. The signature of the variability of the Gulf Stream is evident in the bottom layer for periods of $\approx 90$ days (the eddies range) and $\approx 1$ year. Associated with a seasonal shift in the Gulf Stream position may be a small, out-of-phase, across-slope shift in the Cold Filament location. The observed spatial structure in the velocity field may be due to thermal wind effects associated with the inclination of the transition region above the Cold Filament core.
\end{abstract}

\section{Introduction}

Unlike the seasonal variations of the upper ocean, little is known about seasonal changes at abyssal depths. In the eastern North Atlantic, far from the influences of the Western Boundary Current and mesoscale eddies, Dickson et al. (1982) found a seasonal signal of the eddy kinetic energy in the deep flow and attributed it to the seasonal changes of wind stress and stratification of the upper layers. In the western North Atlantic, if there is some seasonal cycle in deep layers, it is more likely due to seasonal changes in the Gulf Stream system rather than to wind stress or stratification.

The seasonal variability of the Gulf Stream transport is well documented (e.g., Niiler and Richardson, 1973; Worthington, 1976; Molinari et al., 1985), as is the seasonal shift of its location (e.g., Worthington, 1976; Watts, 1983) and its sea

\footnotetext{
${ }^{1}$ Now at: Atmospheric and Oceanic Sciences Program, Princeton University, Princeton, NJ 08542, USA
}

surface height ( $\mathrm{Fu}, 1987)$. Some observations suggest that these seasonal variations may penetrate into abyssal depths as a low-frequency signal in the deep flow. The low-frequency variability of the deep flow, just south of the Gulf Stream, is dominated by eddying events with time scales of about 100 days (Hendry, 1985). Schmitz and McCartney (1982) showed evidence of variations at time scales even longer than the eddies scale, and suggested that they may be related to a contraction of the subtropical gyre. Just north of the Gulf Stream, in the HEBBLE area $\left[\sim\left(40^{\circ} \mathrm{N}, 62^{\circ} \mathrm{W}\right), \sim 4850 \mathrm{~m}\right.$ depth], the near-bottom flows have been found to be correlated with the north-south shift of the Gulf Stream at semimonthly and 40-day periods (Ionov et al., 1986); however, the record was not long enough to consider longer periods. In addition, the near-bottom flows at the HEBBLE site are affected by the overhead passage of warm-core rings. The barotropic component of these rings produce abyssal current fluctuations with time scales of 30 to 90 days (Kelley and Weatherly, 1985; Weatherly and Kelley, 1985a). Therefore, 
there is reason to expect that long-term variability in the Gulf Stream and warm-core rings may result in comparable time-scale changes at great depths. To detect long-term changes (periods $\geqslant 90$ days) is one of the subjects of this study.

As in Ionov et al. (1986), time series of abyssal flows in the HEBBLE area and the Gulf Stream position are examined. However, the records are longer by about 400 days and temperature records are also considered.

A dominant feature at the base of the Scotian Rise is the Cold Filament with which are associated relatively large horizontal gradients of temperatures (Weatherly and Kelley, 1982, 1985b) and apparently velocities (Hogg, 1983). The Rossby radius of deformation for it is about $1 \mathrm{~km}$ (see next section for more details), and thus discussion of the local dynamics at this site should take this into account. A second objective here is to examine current meter records obtained from five moorings, located less than $10 \mathrm{~km}$ apart, for fine spatial structure. Spatial structure in near-bottom flows was described by Kelley and Weatherly (1985), but they considered only three locations with much greater distance between them. This study is therefore distinguished from the previous works that were done in the HEBBLE region by focusing on larger time scales and describing finer spatial structure.

In the first section of this paper the statistical properties and spatial structure of the near-bottom region are examined. In the second section the spectra and the annual patterns of the bottom layer and the Gulf Stream are examined. The third section is a summary and discussion.

\section{Spatial structure}

The current meter records were obtained at five consecutive moorings, located roughly along a northwest to southeast line across the isobaths (Fig. 1). The maximum horizontal spacing and water depth difference between the uppermost mooring, M1, and the lowermost mooring, M3, is about $10 \mathrm{~km}$ and $55 \mathrm{~m}$, respectively, and their order downslope is M1, M2, M4, M5 and M3 (Fig. 1). A 24-h Gaussian filter was applied to the raw data and daily values are examined here. The mean potential temperature, scalar current speed, velocity component along stream, and eddy kinetic energy for each record, all obtained within $20 \mathrm{~m}$ of the bottom, are given in Table 1. In this table, the standard error of each mean value, i.e., the r.m.s. of the difference between the calculated average, $\langle x\rangle$, and the real mean, $X$, was estimated from:

$\left[\left\langle(\langle x\rangle-X)^{2} \cdot\right]^{1 / 2}=2 \sigma^{2} T_{0} / T\right]^{1 / 2}$

(e.g., Tennekes and Lumley, 1972, p. 212) where $\sigma^{2}$ is the variance of $x_{\mathrm{j}}, T$ is the averaging period and $T_{0}$ is the integral time scale taken to be 5 days (Harkema et al., 1986). It is important to note that eqn. (1) assumes negligible seasonal variations. Initially this assumption is made. Inferences will then follow about the Cold Filament structure. Later it will be shown that seasonal variations are non-negligible. However, while weakening the inferences on spatial structure obtained when $T$ is taken as the total measured period, they are not contradicted. In fact, such inferences appear to be true even when considering the seasonal cycle and taking $T$ as a partial period related to specific season (i.e., see the next section).

The mean temperatures and velocities show significant differences, with $\mathrm{M} 5$ being the coldest and the most energetic. The mean temperature at M5 is significantly different from that at M1-M4. Moreover, that at M3 and M4 is also significantly different from that at M1 and M2 (Fig. 2). In this context, two mean values are significantly different if the calculated averages \pm standard error do not overlap. The difference is most remarkable for M2 and M5 with the temperature difference between the two sites $\left(\sim 30 \mathrm{~m}^{\circ} \mathrm{C}\right)$ being one order larger than the standard error $\left(\sim 3 \mathrm{~m}^{\circ} \mathrm{C}\right)$. The instruments at each mooring were at different heights above the bottom $(13 \mathrm{~m} \pm 6 \mathrm{~m})$, but vertical gradients of temperature and velocity do not appear to explain such horizontal differences. For example, data at levels between $5 \mathrm{~m}$ and $20 \mathrm{~m}$ above the bottom (essentially those heights in Table 1) at M4 (Harkema and Weatherly, 1988a) show mean potential temperature and speed differences of $\sim(1$ $\left.\mathrm{m}^{\circ} \mathrm{C}\right)$ and $\sim\left(0.5 \mathrm{~cm} \mathrm{~s}^{-1}\right)$. These results, and the knowledge of the existence of the Cold Filament in this region (hereinafter CF), reinforce the con- 


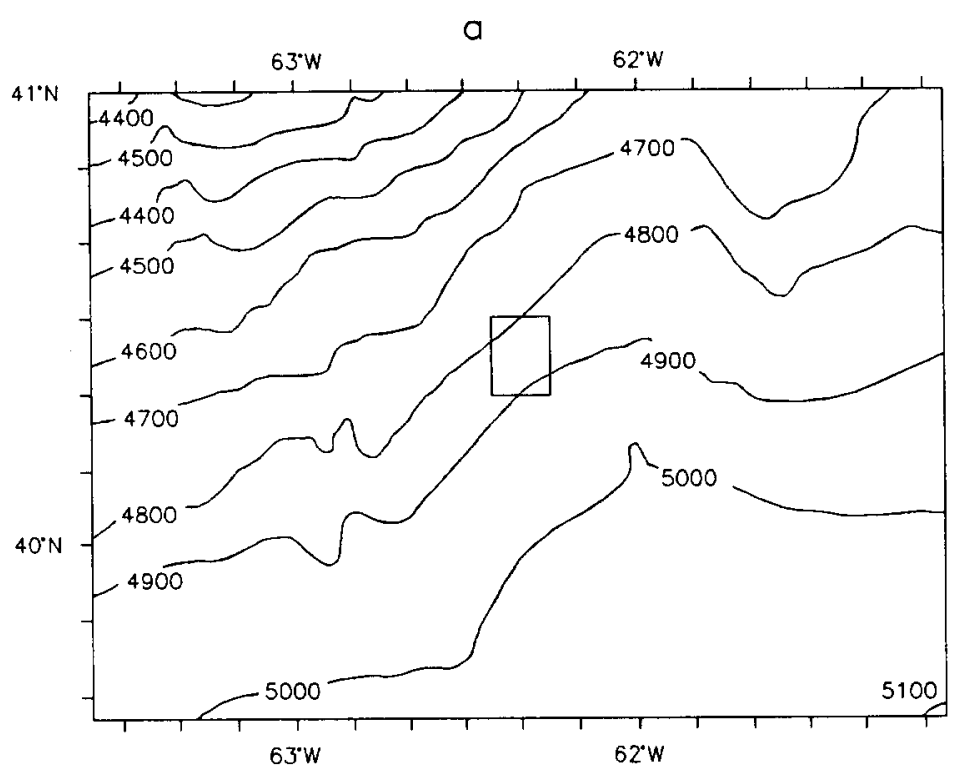

b

Fig. 1. Bathymetric map showing the study area and average velocity vectors at the 5 sites (moorings $1-5$ are indicated as $\mathrm{Ml}-$ M5). The bases of the vectors are positioned at the sites. The rectangle area, indicated between the $4800 \mathrm{~m}$ and the $4900 \mathrm{~m}$ isobaths in (a) is enlarged in (b).

TABLE 1

Summary of mooring locations, periods and mean properties of the bottom layer. In the parentheses are the standard errors (see text) for each mean property

\begin{tabular}{llllll}
\hline Mooring & 1 & 2 & 3 & 4 & 5 \\
\hline Site $40 \mathrm{~N}$ & $27.09^{\prime}$ & $27.15^{\prime}$ & $24.01^{\prime}$ & $25.00^{\prime}$ & $24.30^{\prime}$ \\
$\quad 62 \mathrm{~W}$ & $22.03^{\prime}$ & $20.12^{\prime}$ & $16.04^{\prime}$ & $17.35^{\prime}$ & $16.32^{\prime}$ \\
Water depth $(\mathrm{m})$ & 4800 & 4832 & 4855 & 4845 & 4855 \\
Height $(\mathrm{m})$ & 7 & 3 & 19 & 5 & 10 \\
Period & $2 / 82-$ & $7 / 82-$ & $6 / 83-$ & $9 / 83-$ & $8 / 84-$ \\
& $7 / 82$ & $6 / 83$ & $9 / 83$ & $8 / 84$ & $9 / 85$ \\
Number of days & 160 & 339 & 99 & 336 & 386 \\
Potential & 1.825 & 1.830 & 1.807 & 1.818 & 1.803 \\
temperature $\left({ }^{\circ} \mathrm{C}\right)$ & $(0.003)$ & $(0.003)$ & $(0.004)$ & $(0.003)$ & $(0.004)$ \\
Speed $(\mathrm{cm} / \mathrm{s})$ & 9.5 & 9.6 & 7.9 & 12.5 & 16.1 \\
& $(1.1)$ & $(0.9)$ & $(1.3)$ & $(1.1)$ & $(1.1)$ \\
Along stream & 3.4 & 5.9 & 3.4 & 7.4 & 10.7 \\
velocity $(\mathrm{cm} / \mathrm{s})$ & $(2.9)$ & $(1.4)$ & $(2.2)$ & $(1.8)$ & $(1.7)$ \\
Direction $\left({ }^{\circ}\right)$ & 252 & 244 & 241 & 235 & 264 \\
& $(45)$ & $(7)$ & $(31)$ & $(5)$ & $(10)$ \\
Eddy kinetic & 62 & 43 & 34 & 71 & 94 \\
energy $\left(\mathrm{cm}^{2} / \mathrm{s}^{2}\right)$ & $(17)$ & $(13)$ & $(10)$ & $(12)$ & $(17)$ \\
\hline
\end{tabular}

clusion of Weatherly and Kelley (1985b) that the $\mathrm{CF}$ is a permanent feature in the HEBBLE area. Weatherly and Kelley (1982) indicated the CF as being $\sim 100 \mathrm{~km}$ wide, but it is obvious that $\sim 30$ $\mathrm{km}$ spacing between their CTD (conductivity, temperature and depth) stations cannot distinguish the much finer structure (order of $\sim 10 \mathrm{~km}$ ) indicated here. Weatherly and Kelley (1985b) found some evidence for a front-like structure in the upslope edge of the $\mathrm{CF}$, with horizontal temperature gradients of about $10 \mathrm{~m}^{\circ} \mathrm{C} / 100 \mathrm{~m}$. The coldest potential temperature seen at any of the 


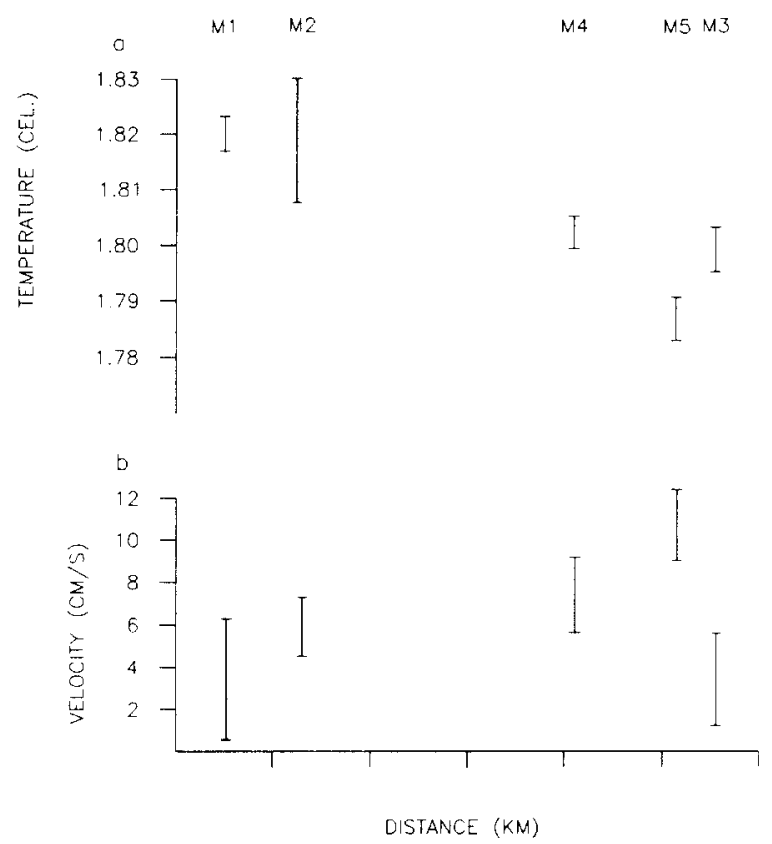

Fig. 2. Range of the average values (average \pm standard error): (a) potential temperature, (b) along-stream velocity. The relative location of the five sites from northwest to southeast are indicated by M1, M2, M4, M5 and M3, respectively.

stations was $1.72^{\circ} \mathrm{C}$ at $\mathrm{M} 5$. This is $\sim 50 \mathrm{~m}^{\circ} \mathrm{C}$ colder than the lowest temperature seen at the other stations. Therefore, the interpretation of the spatial structure, with respect to the mooring locations, is as follows: M5 was probably very near the center of the core of the CF, M3 and M4 were located near its downslope and upslope edges, respectively, while M1 and M2 were located father upslope outside the $\mathrm{CF}$.

Since the CF is exposed to energetic fluctuations from the Gulf Stream and rings, some upslopedownslope fluctuations about its position, as suggested by Kelley and Weatherly (1985), appear likely. Therefore, the spatial structure of temperature, indicated by the average values, may be clearly different from the instantaneous structure (such as that found, for instance, by CTD profiles). In order to approximate the horizontal crosssection of the CF (without making any assumptions about the type of fluctuations involved), the following was done. The CF edge (i.e., the surface between the transition region and the exterior) was taken to be the $1.82^{\circ} \mathrm{C}$ potential temperature isotherm (following Weatherly and Kelly, 1982, 1985b), and the CF core edge (i.e., the surface between the mixed layer and the transition region) was taken to be the $1.80^{\circ} \mathrm{C}$ and less than $1.82^{\circ} \mathrm{C}$ was calculated for each record. These values (i.e., fraction of time as a function of location) were found to be approximated by a Gaussian-like function of the form:

$$
P(x)=P_{0} E \times P\left[-\left(x / x_{0}\right)^{2 b}\right]
$$

where $P_{0}$ is the value of $P$ at M5 (at $x=0$ ). Figure 3 shows that with $P_{0}^{1.80}=0.72, x_{0}^{1.80}=$ $4.9 \mathrm{~km}, P_{0}^{1.82}=0.91, x_{0}^{1.82}=13.9 \mathrm{~km}$ and $b^{1.80}=$ $b^{1.82}=2 / 3$ (where the superscripts indicate the temperature range in which they apply), eqn. (2) agrees well with the observations. Since only few observations were available in the down-slope region of the CF (apparently only M3, which is a relatively short record, was in this region), the estimated structure is based on the assumption that the CF is symmetric and centered around M5. Therefore, although Fig. 3 may differ somewhat from the total structure of the $\mathrm{CF}$, half this width is believed to be a reasonable estimate for the mean upslope benthic front of the CF. Equation (2) was then used to extrapolate the temperature structure into

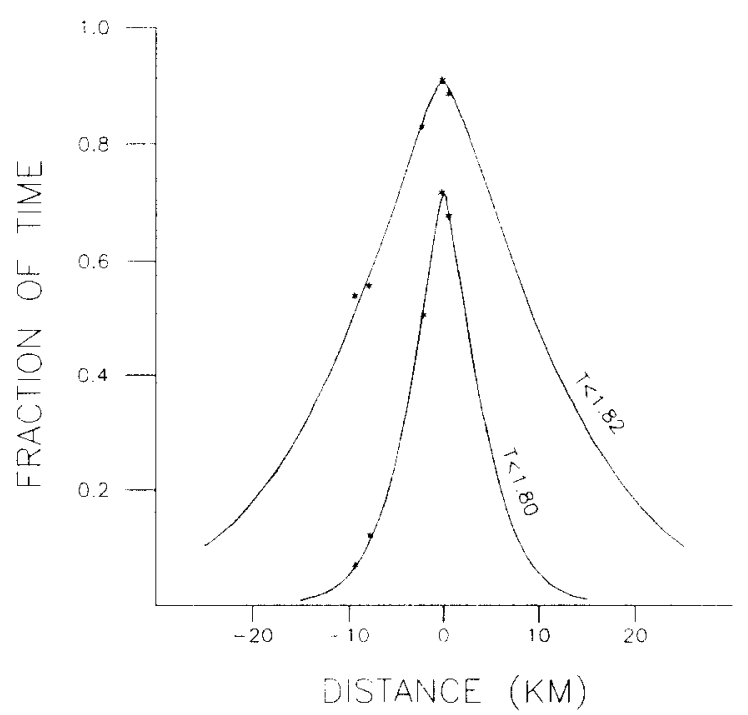

Fig. 3. Spatial temperature structure: portion of time in which a potential temperature was less than $1.80^{\circ} \mathrm{C}$, or less than $1.82^{\circ} \mathrm{C}$ at each location. Stars indicate observational values (mooring M5 is located at the center and the other moorings respectively as in Figs. 1 and 2). Solid lines are the empirical functions defined by eqn. (2). 
regions where observations were not available. Defining the range of the CF extension, $A$, as the region where $\mathrm{CF}$ temperatures can be found at least $1 \%$ of the time, (i.e., $P(A / 2)=0.01$ ), gives $A^{1.80}=29 \mathrm{~km}$ and $A^{1.82}=86 \mathrm{~km}$. Next, how much of this range was actually occupied by the instantaneous CF was approximated. The area of the rectangle $-A / 2<x<A / 2,0<P<1$ is $A$, and thus the area under each curve in Fig. 3 (i.e., the integral of $P$ over $x$ from $-A / 2$ to $A / 2$ ) represents the average portion of $A$ occupied by the CF. Since most of the contribution to that integral comes from the center section, the instantaneous width, $a$, is approximately where $Q$ is the gamma function. Therefore, the CF average crosssections with respect to the two temperature ranges are $a^{1.80}=7 \mathrm{~km}$ and $a^{1.82}=23 \mathrm{~km}$. By the above approximations, the $\mathrm{CF}$ is estimated to occupy about $25 \%$ of its total amplitude of fluctuations.

A representative thickness of the $\mathrm{CF}$ is about $100 \mathrm{~m}$, and representative temperature change across it, $\delta T$, in the vertical is about $0.04^{\circ} \mathrm{C}$ (Weatherly and Kelley, 1982). Thus with $g^{\prime}=$ $-0.09 \delta T$ (Weatherly and Kelley, 1982), the Rossby radius of deformation $R_{\mathrm{D}}=\left(g^{\prime} h\right)^{1 / 2} / f \approx 1 \mathrm{~km}$ for $f=10^{-4} \mathrm{~s}^{-1}$. Therefore, the estimated $a^{1.80}$ and $a^{1.82}$ above are not unreasonable in that they are a few $R_{\mathrm{d}}$ 's. Nof (1983), for example, showed that a cold eddy on a sloping bottom has a radius of at least $4 R_{\mathrm{d}}$.

Considering now the spatial velocity structure, Fig. 2 indicates that the CF core is also a region of statistically significant stronger flows, and that the cross-stream shear is $\sim\left(7 \mathrm{~cm} \mathrm{~s}^{-1}\right) / 10 \mathrm{~km}$ for the upslope edge, and $\sim\left(7 \mathrm{~cm} \mathrm{~s}^{-1}\right) / 2 \mathrm{~km}$ for the downslope edge. Such shears are large even for near-surface flows. M5 is further distinguished by having a flow direction of about $30^{\circ}$ upslope with respect to the other sites (Fig. 1), and this difference appears to be a significant (cf. M4 and M5 in Table 1). The M5 flow direction difference may be a real feature of the CF or a local topographic effect. Whatever the cause, it apparently affects the flow equally at $100 \mathrm{~m}$ above the bottom as at 10 $\mathrm{m}$ above the bottom. Current meters at both levels at M5 gave essentially the same flow direction (Harkema and Weatherly, 1988b). Note that M3 and $\mathrm{M} 1$, located at the edges of the investigated region, have greater variability in the current direction than the other records (Table 1), suggesting that the CF may not only be more energetic, but also a more stable feature than the surrounding flow.

\section{Spectral analyses and the annual pattern}

In order to produce a time series for analysis, the following steps were applied to the data: (a) subtracting the average potential temperature of each mooring from the daily values; (b) connecting the five consecutive, normalized temperature records to form one daily-averaged time series of 1320-day duration; (c) calculating 15-day average time series of temperature, fluctuating kinetic energy, and mean kinetic energy; (d) normalizing the 15-day averages of the fluctuating and the mean kinetic energy records by the mean values of each mooring. The fluctuating kinetic energy for each 15-day period is calculated by:

$F K E=1 / n \sum_{i=1}^{n} 1 / 2\left[\left(u_{\mathrm{i}}-U\right)^{2}\left(v_{\mathrm{i}}-V\right)^{2}\right]$

where $n=15$ and $U$ and $V$ are the average velocity components of the mooring that this period belongs to. The mean kinetic energy for each 15-day period is calculated by:

$M K E=1 / 2\left(\langle u\rangle^{2}+\langle v\rangle^{2}\right)$

where $\langle u\rangle$ and $\langle v\rangle$ are the average velocity components of this period. The choice of a 15-day period is a compromise. On one hand, the high-frequency fluctuations, especially the semimonthly periodicity (Kelly et al., 1982; Kelly and Weatherly, 1985) should be eliminated. On the other hand, there should be enough data points for the spectral analyses. As was shown, there are significant differences between the five records that appear to be due to the spatial structure of the Cold Filament. Therefore, the normalization of the kinetic energy values with respect to each mooring, is an attempt to eliminate the spatial differences. The time series that were produced by the above procedure thus represent the long, time-dependent fluctuations about the mean values. The time series of the surface Gulf Stream position at $62^{\circ} \mathrm{W}$ (see 
Ionov et al., 1986, for more details) was used to calculate 15-day average time series for the same period as the bottom layer records. The crossspectra between the temperature, FKE and MKE records, with the Gulf Stream position record (hereafter referred to as GSP) were smoothed with 3 passes of a simple Hanning spectral window.

At the mesoscale eddy scale band, an energetic peak, with a period of $\sim 90$ days, which is marginally significant at the $90 \%$ confidence level is found in all the spectra except the MKE (Fig. 4a-d). At this band, a $5 \%$ significance level coherency can be found between the FKE and the GSP series (Fig. $4 \mathrm{~g}$ ), but only $10 \%$ significance level coherency is found between the temperature and the GSP
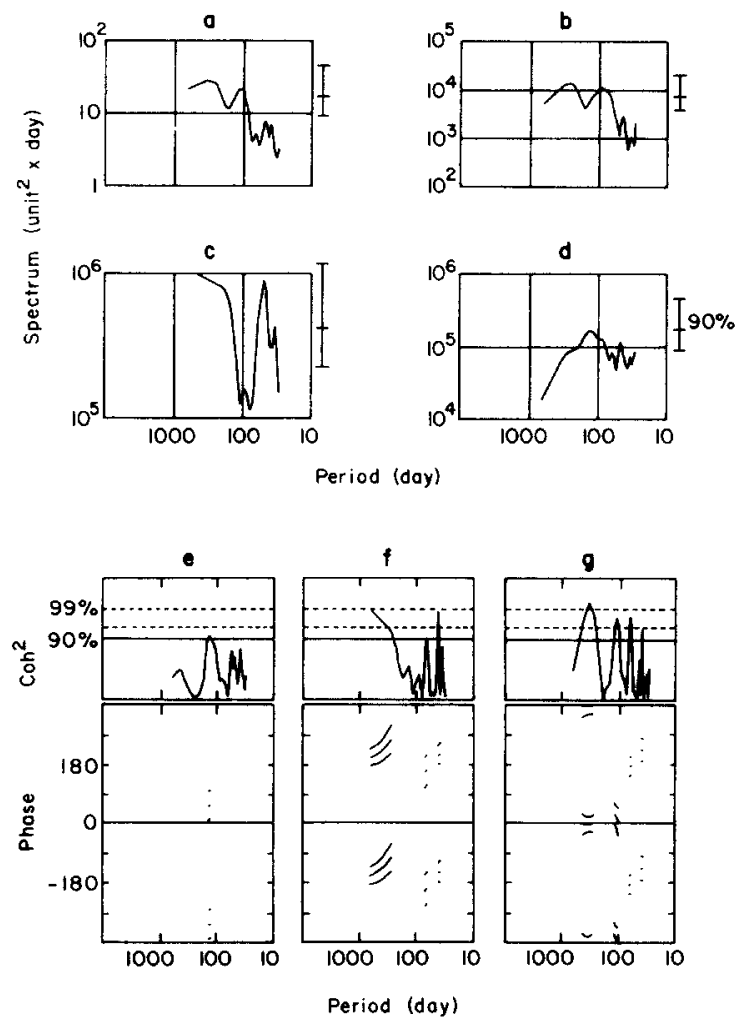

Fig. 4. Spectra: (a) GSP (units latitude). (b) potential temperature $\left(\mathrm{m}^{\circ} \mathrm{C}\right)$. (c) MKE $\left(\mathrm{cm}^{2} \mathrm{~s}^{-2}\right)$. (d) FKE $\left(\mathrm{cm}^{2} \mathrm{~s}^{-2}\right)$. Bars indicate $90 \%$ confidence intervals. Coherency squared and phase differences between the GSP and: (e) potential temperature, (f) MKE, and (g) FKE. The solid line and the dashed lines above it indicate $90 \%, 95 \%$ and $99 \%$ confidence levels $(10 \%, 5 \%$ and $1 \%$ significance levels), respectively. Phase is shown for the bands of coherency with a more than $90 \%$ confidence level. series (Fig. 4e). That the FKE is with phase with the GSP, is not unexpected since the GSP at $62^{\circ} \mathrm{W}$ reflects local meandering of the Gulf Stream and warm-core eddies activity (Ionov et al., 1986).

The seasonal-annual frequency band, can be seen as the most energetic of all the spectra, except in the FKE series, but with a confidence level less than $90 \%$ (Fig. $4 \mathrm{a}-\mathrm{d}$ ). For this band, longer records are needed in order to get high statistical significance levels. However, the records were long enough to indicate coherencies in this band. Near annual frequency the MKE and the FKE have $5 \%$ and $1 \%$ significance level coherencies with the GSP, respectively. However, the MKE has opposite phase with the GSP, while the FKE has the same phase as the GSP (Fig. $4 \mathrm{f}$ and $\mathrm{g}$ ). The annual cycle of the Gulf Stream transport and position can be described generally as bimodal, a southern position mode with large transport, and a northern position mode with small transport (e.g., Worthington 1976). Larger variability of the GSP occurs when it is in its southern mode with large transport, and a northern position mode with small transport (e.g., Worthington, 1976). Larger variability of the GSP occurs when it is in its southern mode (Ionov et al., 1986). Therefore, an opposite phase between the mean flow and the variability of the Gulf Stream are indicated by the MKE and the FKE records, respectively. The cross-spectra show that this cycle results in an annual cycle in the kinetic energy of the bottom layer. The southern (northern) position mode is characterized by large (small) mean transport in the deep recirculation, i.e., large (small) $\mathrm{MKE}$, and small (large) variability, i.e., small (large) FKE. Note the absence of coherency between the temperature and the GSP at this band. It will be shown later that this may be a result of a seasonal change in the CF structure.

The cross-spectra show clearly that a band of very high coherency of Gulf Stream displacement and near-bottom flows exists at long periods of about a year. This annual pattern is now discussed in more details in terms of the Cold Filament structure. The three longest records (M2, M4 and M5), each one of about one year duration, were filtered by a 90 -day running average, in order to reduce the fluctuations at the eddies band. The 
annual distribution of the 15-day averaged, filtered values of temperature, mean kinetic energy (normalized as before), and the Gulf Stream position at $62^{\circ} \mathrm{W}$, are shown in Fig. 5. The Gulf Stream displacement at $62^{\circ} \mathrm{W}$, shows a similar general pattern as described before by many authors (e.g., Worthington, 1976), i.e., the Gulf Stream is shifted southward in late winter-early spring, and northward in late autumn. A bimodal seasonal pattern is found also in most of the bottom layer records. For convenience, the two modes are called the "spring-mode" and the "autumn-mode", respec-
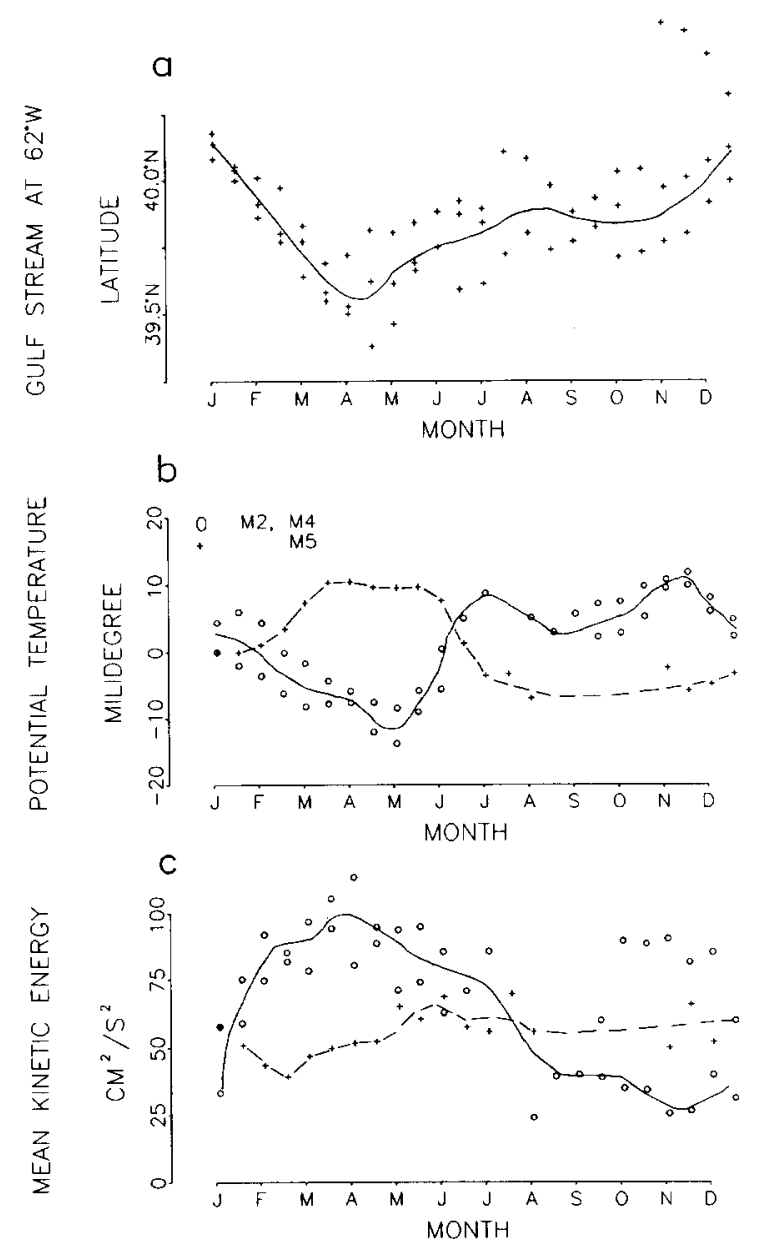

Fig. 5. Annual distribution: (a) Gulf Stream position at $62^{\circ} \mathrm{W}$; (b) potential temperature changes; and (c) mean kinetic energy. The values are 15-day averaged, 90-day filtered, and the mean kinetic energy is normalized as described in the text. Values at sites M2 and M4 are indicated by circles; values at site M5 are indicated by +'s. The lines in (b) and (c) represent approximated average levels. tively. However, a signature of the spatial structure previously described can be seen as different patterns at the M5 site and at the M2 and M4 sites. The "spring-mode" period at M2 and M4 is characterized by relatively large MKE and low temperatures while the "autumn-mode" period is characterized by smaller MKE and higher temperatures. Five points of high MKE at OctoberDecember are out of this pattern (Fig. 5c), but they relate to an extreme, unusual northern Gulf Stream position at that time (Fig. 5a). When the Gulf Stream mean position is to the north of the measured site, the HEBBLE area may be affected by the recirculation gyre south of the Gulf Stream, and thus controlled by different processes than those described here. However, the general pattern is consistent with the cross-spectra findings that the bottom layer is more energetic when the Gulf Stream position is further south (during the "spring-mode" when the Gulf Stream transport is larger). At the M5 site (which is thought to be near the core of the Cold Filament), the annual pattern of temperature seems to be in opposite phase to that at M2 and M4. There is some indication of an annual pattern in MKE at M5, but since the distinguished pattern of M5 is less obvious in the MKE than in the temperature, this may explain why the spectrum of the MKE (which includes all the mooring records) shows coherency with the GSP at the annual band, but the temperature spectrum does not. The MKE at M5 is almost constant with very small seasonal variability, which indicates again that the $\mathrm{CF}$ is a stable feature. The different patterns over such small distance ( $\sim 2 \mathrm{~km}$ between M4 and M5), support the previous finding of spatial fine structure in the Cold Filament.

Defining the "spring-mode" from January to June, and the "autumn-mode" from July to December, the average values of temperature and velocity for each period (when available) are clearly different at all the sites except at M5 (Fig. 6). In such a case of seasonal effect, one must be wary of using long period average values and an integral time scale to estimate the appropriate range of the real mean value. Note again, the distinction of mooring M5 from the others in both the temperature and the velocity, where all the moorings, 


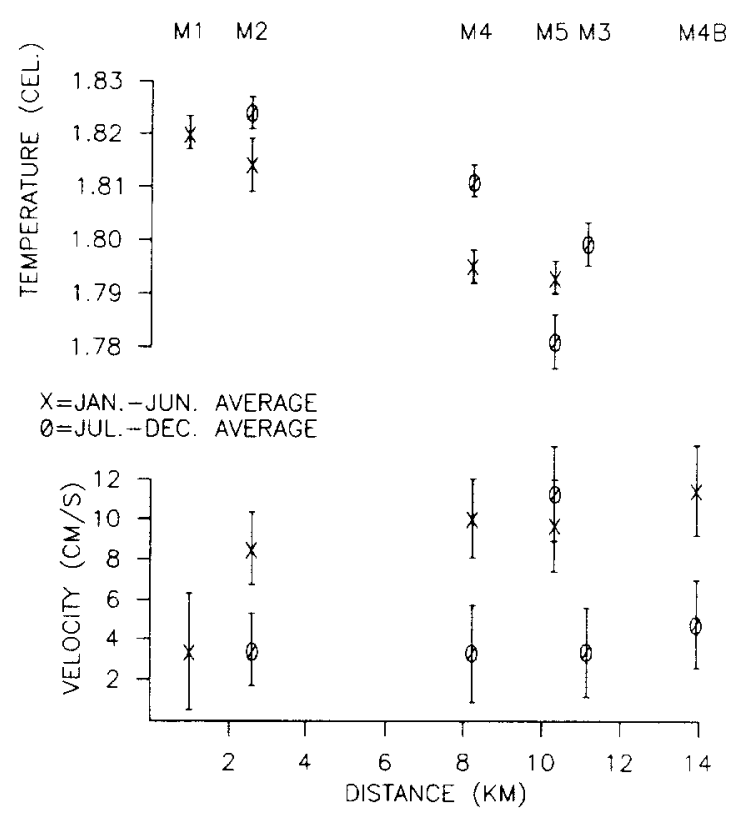

Fig. 6. Same as Fig. 2., but the averages and the errors were calculated separately for two periods: from January to June (indicated by $x$ ), and from July to December (indicated by 0 ). Monitor M4b (not included in Fig. 2 since it is located at $100 \mathrm{~m}$ above the bottom and not in the bottom layer) is added for comparison.

except M5, are more energetic and colder in the spring period. In Fig. 6 an additional record, M4b, is included. It was obtained at $100 \mathrm{~m}$ above the bottom, and thus, unlike the records previously considered, above the bottom layer. Records available at M4 and M5 show a marked similarity in velocity in and above the bottom layer, but a marked dissimilarity in the corresponding temperature records. Since the intent here is to consider the bottom layer, only M4b's velocity data is presented in Fig. 6.

In order to approximate the average temperature structure at each period, other instruments higher above the bottom (not included in Table 1) were used. These were at the following heights: $(40 \mathrm{~m}$, $60 \mathrm{~m}, 100 \mathrm{~m}),(10 \mathrm{~m}, 30 \mathrm{~m}, 100 \mathrm{~m}),(30 \mathrm{~m}, 45 \mathrm{~m}$, $75 \mathrm{~m}, 100 \mathrm{~m}, 200 \mathrm{~m})$, and $(100 \mathrm{~m})$ at $\mathrm{M} 1, \mathrm{M} 2$, $M 4$, and M5, respectively. The average location of the Cold Filament seems to be more upslope during the "spring-mode" period, and more downslope during the "autumn-mode" period (Fig. 7). The amplitude of this across-slope shift of the core of the Cold Filament (potential temperature less

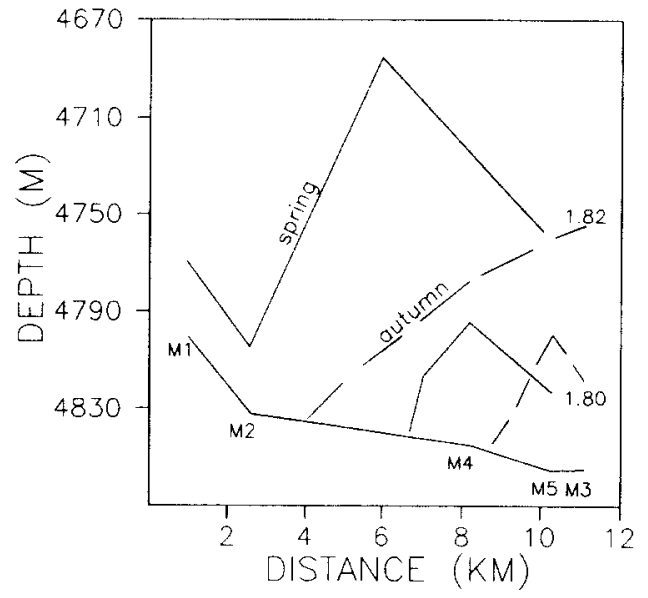

Fig. 7. The average potential temperature structure of the Cold Filament. Solid lines are the $1.80^{\circ} \mathrm{C}$ and $1.82^{\circ} \mathrm{C}$ isotherms at the "spring mode" period (January-June). Dashed lines are the $1.80^{\circ} \mathrm{C}$ and $1.82^{\circ} \mathrm{C}$ isotherms at the "autumn mode" period (July-December). The locations of the five moorings are indicated by $\mathbf{M} 1-\mathbf{M} 5$.

than $1.80^{\circ} \mathrm{C}$ ) appears to be small, $\sim 2 \mathrm{~km}$, but the amplitude of the shift of the $1.82^{\circ} \mathrm{C}$ isotherm is probably greater. During the "spring-mode" period, the Cold Filament is also wider, as indicated by Fig. 6 . Note that the "inertial" oscillations in the cross-slope direction of a cold eddy on a sloping bottom (in much shorter time scales, $\sim 1 / f$ ) have amplitude order $g^{\prime} / f^{2}$ (Nof, 1984). This value, $\sim 100 \mathrm{~m}$, is smaller than the amplitude of the seasonal oscillations, and is much smaller than the amplitude of the eddy-driven fluctuations. Such a seasonal bimodal pattern of the Cold Filament (Fig. 7) can explain the observed spatial difference of the annual patterns: with the Cold Filament shifted further upslope during the spring, the upslope sites (M2 and M4) become colder, while the downslope site M5 becomes warmer (Fig. 6).

Another possible effect of this seasonal shift is on the horizontal velocity gradients. The magnitude of the slope of each front in Fig. 7 is approximated by $|\mathrm{d} h / \mathrm{d} x|=200 \mathrm{~m} / 4 \mathrm{~km}$. Now, due to the thermal wind effect, this inclined front can produce a geostrophic velocity component relative to the exterior of magnitude:

$\mathrm{V}_{G}=\left(g^{\prime} \mid f\right)|\mathrm{d} h / \mathrm{d} x| \approx 2 \mathrm{~cm} \mathrm{~s}^{-1}$

Therefore, in the downslope region of the CF (where the thermal wind effect supports the south- 
ward flow of the exterior), the velocity can be as much as $4 \mathrm{~cm} \mathrm{~s}^{-1}$ larger than the flow in the upslope region (where this effect reduces the velocity). Figure 7 shows that during the spring period most of the moorings were (in average) under thermal wind effect supporting the mean flow, while during the autumn period they were under opposed thermal wind effect (maybe except at M3 and M5 where the structure is not well defined due to lack of observations as mentioned before). The above pattern could explain the seasonal differences in the average velocities as indicated in Fig. 6. Thus, although the seasonal variability is evident in the velocity records, we hesitate to conclude what portion of this variability is a direct effect of changes in the forcing velocity, and what portion is a secondary effect due to the shift of the Cold Filament.

\section{Summary and discussion}

The purpose of this study was to examine benthic layer data from the HEBBLE area for small spatial scale structure $(<10 \mathrm{~km})$ and long-term ( $\sim 90$ to $\sim 400$ days) variability. The former is thought to be related to the existence of the Cold Filament (its $R_{\mathrm{d}} \approx 1 \mathrm{~km}$ ), and the latter to longterm variability in the Gulf Stream system. The main results of this study are the following.

(a) The data indicate that mean values of potential temperature and current can change by $\approx 40$ $\mathrm{mC}$ and $\approx 7 \mathrm{~cm} \mathrm{~s}^{-1}$ horizontally over a region of extent less than $10 \mathrm{~km}$ width. These changes are thought to be due to the CF. The former is not a new feature (Weatherly and Kelley, 1985b); however, the latter is. The current direction also appears to change by $\approx 30^{\circ}$ towards upslope at the so-called core region of the CF (M5). However, whether this is a feature of the CF or due to an unidentified topographic or other effect is not known. It is interesting that in another deep western boundary flow, Fukasawa et al. (1987) also noted a marked upslope flow component.

(b) The Cold Filament is a permanent feature of the HEBBLE area, affecting a range of some $100 \mathrm{~km}$, as previously suggested by Weatherly and Kelley (1985b), but it has a finer structure in its core and in its front-like edges with horizontal scales of the order of the Rossby radius of deformation. The Cold Filament core is about $7 \mathrm{~km}$ wide, but its location fluctuates about the mean position with amplitudes four times larger than its instantaneous width. The total width of the CF appears to be about $25 \mathrm{~km}$. The above conclusions about the CF width depend on rather limited data from what has been called here its downslope portion. It is up to further studies to show whether these conclusions are indeed valid. The Gulf Stream width is several times its Rossby radius of deformation; perhaps the same is true for the CF. If correct, this indicates that in the CF twodimensional models are probably required to accurately predict the bottom boundary layer.

(c) The kinetic energy and the potential temperature of the near-bottom layer are highly correlated with the variations of the Gulf Stream system at the eddies and at the annual time scales. About the $C F$ core a clear annual variation is apparent in temperature and velocity.

(d) The bimodal pattern of the Gulf Stream appears to result in a bimodal pattern of the Cold Filament. In late winter-early spring when the Gulf Stream is in its southern mode, the Cold Filament is shifted to its northern (upslope) mode, and in late autumn when the Gulf Stream is in its northern mode, the Cold Filament is in its southern (downslope) mode. In the first period, when the Gulf Stream flux is larger, the bottom flow is also larger and the Cold Filament is wider.

(e) A simple analysis indicates that thermal wind effects associated with the inclination of the transition layer above the bottom mixed layer could account for the observed horizontal velocity gradients.

And a final comment: although this study shows a seasonal variability at abyssal depths, the Cold Filament amplifies this signal and thus a seasonal cycle in other deep regions is not expected to be as remarkable as the one described here.

\section{Acknowledgements}

We thank D. Hunley, J. Ritch and R. Harkema who helped in obtaining and analyzing the data. Support for this work was provided by the Office of Naval Research under contract N00014-82-C- 
0404 as part of the High Energetic Benthic Boundary Layer Experiment (HEBBLE) program.

\section{References}

Dickson, R.R., Gould, W.J., Gurbutt, P.A. and Killworth, P.D., 1982. A seasonal signal in ocean currents to abyssal depths. Nature, 295: 193-198.

Fu, L.L., Vazquez, J. and Parke, M.E., 1987. Seasonal variability of the Gulf Stream from satellite altimetry. J. Geophys. Res., 92: 749-754

Fuglister, F.C., 1951. Annual variations in current speeds in the Gulf Stream system. J. Mar. Res., 1: 119-127.

Fukasawa, M., Teramoto, T. and Taira, K., 1987. Abyssal current along the northern periphery of Shikoku Basin. J. Oceanogr. Soc. Jpn., 42: 459-472.

Harkema, R. and Weatherly, G.L., 1988b. A Compilation of Moored Current Meter Data at the HEBBLE Site, August 1984-September 1985. Department of Oceanography Technical Report CMF-88-02, Florida State University, $80 \mathrm{pp}$.

Harkema, R., Ezer, T. and Weatherly, G.L., 1986. A Compilation of Moored Current Meter Data at the HEBBLE Site, July 1982- September 1983. Department of Oceanography Technical Report CMG-86-01, Florida State University, 125 pp.

Hendrey, R.M., 1985. Deep circulation south of the Gulf Stream at $50^{\circ}$ W. Prog. Oceanogr., 14: 191-207.

Hogg, N., 1983. A note on the deep circulation of the western North Atlantic: its nature and causes. Deep-Sea Res., 30: 945-961.
Ionov, V.V., Weatherly, G.L. and Harkema, R., 1986. On the temporal variability of the surface Gulf Stream and near bottom flows. J. Geophys. Res., 91: 2661-2666.

Kelley, E.A., Weatherly, G.L. and Evans, J.C., 1982. Correlation between surface Gulf Stream and bottom flow near 5000 meter depth. J. Phys. Oceanogr., 12: 1150-1153.

Molinari, R.L., Wilson, W.D. and Leaman, K., 1985. Volume and heat transports of the Florida Current: April 1982 through August 1983. Science, 227: 295-297.

Niiler, P.P. and Richardson, W.S., 1973. Seasonal variability of the Florida Current. J. Mar. Res., 31: 144-167.

Nof, D., 1983. The translation of isolated cold eddies on a sloping botom. Deep-Sea Res., 30: 171-182.

Nof, D., 1984. Oscillatory drift of deep cold eddies. Deep-Sea Res., 31: 1395-1414.

Schmitz, W.J. and McCartney, M.S., 1982. An example of long-term variability of surface current and hydrographic patterns in the western North Atlantic. J. Mar. Res., Suppl., 40: 707-726.

Tennekes, H. and Lumley, J.J., 1972. A First Course in Turbulence. MIT Press, $300 \mathrm{pp}$.

Watts, D.R., 1983. Gulf Stream variability. In: A.R. Robinson (Editor), Eddies in Marine Science. Springer, pp. 114-144.

Weatherly, G.L. and Kelley, E.A., 1982. "Too cold" bottom layers at the base of the Scotian Rise. J. Mar. Res., 40: 9851012 .

Weatherly, G.L. and Kelley, E.A., 1985a. Storms and flow reversals at the HEBBLE site. Mar. Geol., 66: 205-218.

Weatherly, G.L. and Kelley, E.A., 1985b. Two views of the Cold Filament. J. Phys. Oceanogr., 15: 68-81.

Worthington, L.V., 1976. On the North Atlantic Circulation. The Johns Hopkins Press, 110 pp. 